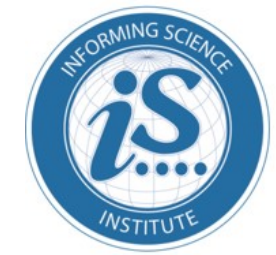

Proceedings of the Informing Science + Information Technology Education Conference

An Official Publication

of the Informing Science Institute

InformingScience.org

InformingScience.org/Publications

Online July 7-8, 2020

\title{
WHAT IS RESEARCH RIGOR? LESSONS FOR A TRANSDISCIPLINE [ABSTRACT]
}

T. Grandon Gill*

Thomas R. Gill

* Corresponding author
University of South Florida, Tampa, FL, USA

University of South Florida, Tampa, FL, USA grandon@usf.edu

thomasgill@,usf.edu

ABSTRACT

Aim/Purpose

Background

Methodology

Contribution

Findings

Recommendations for Practitioners

Recommendations for Researchers

Impact on Society
Use of the term "rigor" is ubiquitous in the research community. But do we actually know what it means, and how it applies to transdisciplinary research?

Too often, rigor is presumed to mean following an established research protocol scrupulously. Unfortunately, that frequently leads to research with little or no impact.

We identify a sample of 62 articles with "rigor" in the title and analyze their content in order to capture the range of perspectives on rigor. We then analyze how these findings might apply to informing science.

This paper offers an approach to defining rigor that is theory based and appropriate for transdisciplinary research.

Rigor definitions tend to fall into one of two categories: criteria-based and compliance-based. Which is appropriate depends on the research context. Even more variation was found with respect to relevance, which is often used as a catch-all for research characteristics that aren't associated with rigor.

Recognize that when researchers are referring to rigor and relevance, they often mean these to apply to other researchers rather than to practice. When funding research, it is important to understand who the rigor and relevance are directed towards.

When using the term "rigor", think carefully about which meaning is intended and be transparent about that meaning in your writing.

A great deal of public money is invested in achieving research rigor. Society should be aware of what it is buying with that funding.

This Proceedings paper was revised and published in the journal Informing Science: The International Journal of an Emerging Transdiscipline, 23, 47-76. https://doi.org/10.28945/4528

(CC BY-NC 4.0) This article is licensed to you under a Creative Commons Attribution-NonCommercial 4.0 International License. When you copy and redistribute this paper in full or in part, you need to provide proper attribution to it to ensure that others can later locate this work (and to ensure that others do not accuse you of plagiarism). You may (and we encourage you to) adapt, remix, transform, and build upon the material for any non-commercial purposes. This license does not permit you to use this material for commercial purposes. 
Future Research Developing a better understanding of research fitness and the factors that contribute to it.

Keywords rigor, relevance, resonance, interdisciplinary, transdisciplinary, research

\section{BIOGRAPHIES}

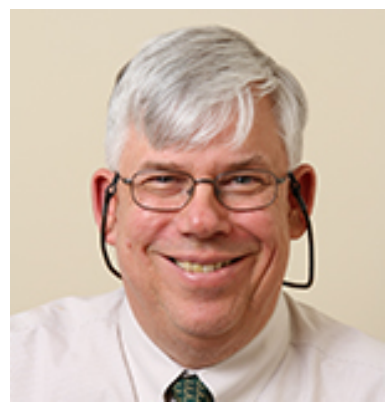

Grandon Gill is a professor in the Information Systems and Decision Sciences Department of the University of South Florida. He is also the Academic Director of the Doctor of Business Administration Program at the Muma College of Business. He is Editor-in-Chief of the Muma Business Review and the past Editor-in-Chief of Informing Science: The International Journal of an Emerging Transdiscipline and the Journal of IT Education: Discussion Cases, also serving as a Governor and Fellow of the Informing Science Institute, where he was elected President in 2019. He was also the inaugural recipient of the Zbigniew Gackowski Award for informing science research

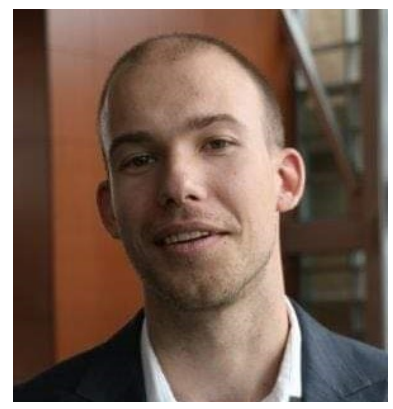

Thomas R. Gill is a doctoral student in the Information Systems and Decision Sciences Department at the University of South Florida. He has a Bachelor of Science in Computer Science from the College of William and Mary and a Master of Science in Business Analytics and Information Systems from the University of South Florida. He co-authored an article published in Cancer Informatics. 